This item was submitted to Loughborough's Research Repository by the author.

Items in Figshare are protected by copyright, with all rights reserved, unless otherwise indicated.

\title{
Assisting design for manufacture using the data model driven approach
}

PLEASE CITE THE PUBLISHED VERSION

PUBLISHER

Professional Engineering Publishing / @ IMechE

VERSION

VoR (Version of Record)

LICENCE

CC BY-NC-ND 4.0

REPOSITORY RECORD

Borja, V., R. Bell, and Jennifer A. Harding. 2019. "Assisting Design for Manufacture Using the Data Model Driven Approach”. figshare. https://hdl.handle.net/2134/4673. 
This item was submitted to Loughborough's Institutional Repository (https://dspace.lboro.ac.uk/) by the author and is made available under the following Creative Commons Licence conditions.

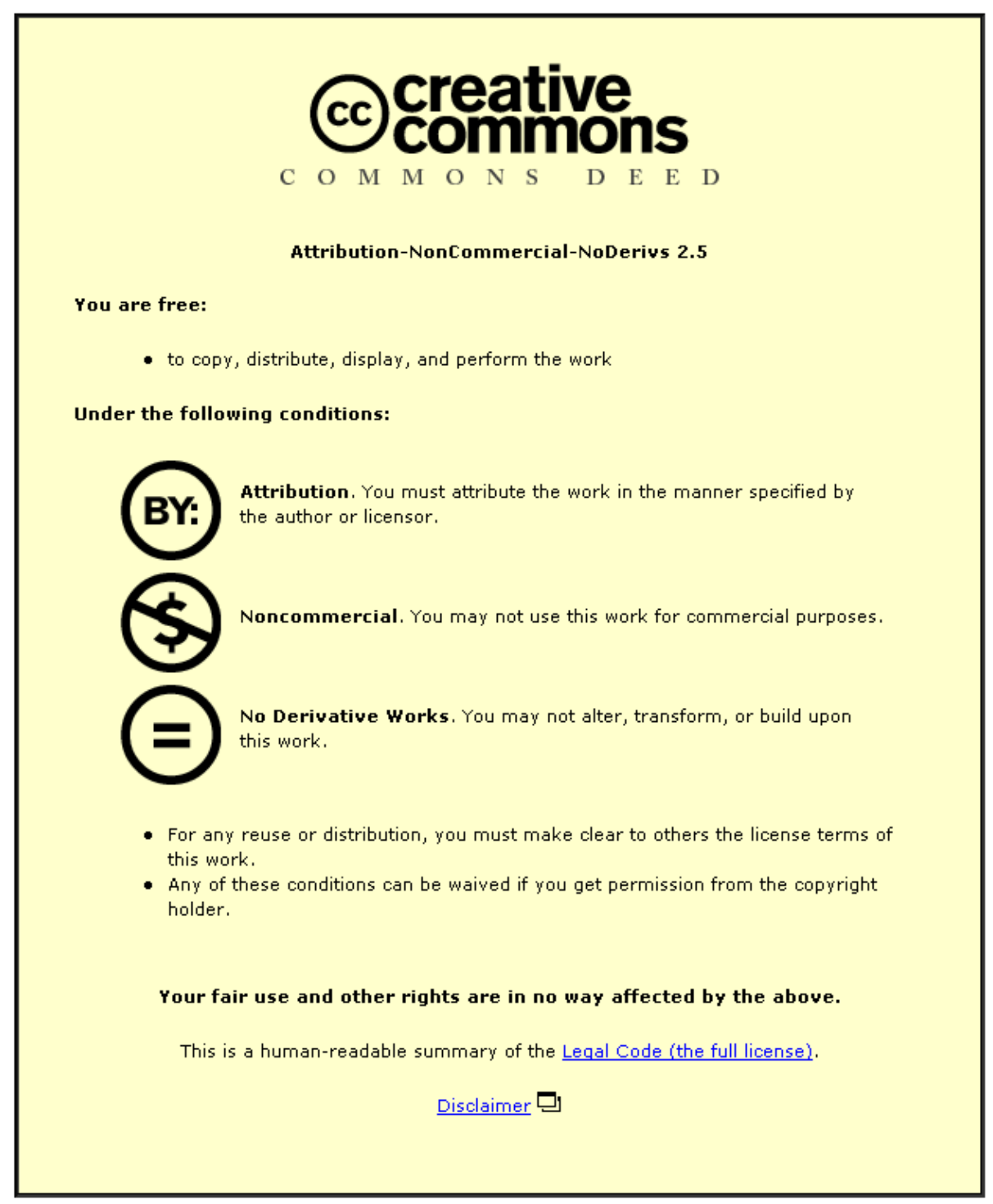

For the full text of this licence, please go to: http://creativecommons.org/licenses/by-nc-nd/2.5/ 


\title{
Assisting design for manufacture using the data model driven approach
}

\author{
V Borja ${ }^{1}$, R Bell ${ }^{2}$ and $\mathbf{J}$ A Harding ${ }^{2 *}$ \\ ${ }^{1}$ Facultad de Ingeniería, Centro de Diseño y Manufactura, Universidad Nacional Autónoma de México, México \\ ${ }^{2}$ Wolfson School of Mechanical and Manufacturing Engineering, Loughborough University, Leicestershire, UK
}

\begin{abstract}
The data model driven approach argues that computer aided engineering systems should be based on information data models in order to properly support the concurrent design of products. These models are the foundation for database representations of products and factories, and enable information sharing across unlinked software applications that address different stages of the product life cycle. This paper presents a product data model capable of capturing product life cycle information, and in particular its utilization for representing manufacturing information is described. A manufacturing data model that depicts the capabilities of manufacturing cells in terms of their processes and resources is also introduced. The potential benefits of using these data models to support design for manufacture are shown through a case study. The case study includes implementation of the models, their utilization representing a product and three manufacturing facilities, and demonstrates their value in the redesign of a component.
\end{abstract}

Keywords: data model driven design, product models, design for manufacture, redesign

\section{INTRODUCTION}

Current investigations explore computer aided engineering (CAE) systems based on information models which capture different elements of the concurrent engineering design of products [1]. These systems are integrated with software application environments [e.g. computer aided design (CAD) programs, solid modellers and design for manufacture expert systems] in open architectures [2]. Data model driven systems such as these, simultaneously support the design of products from different perspectives and the manufacturing process design by enabling data sharing through their data models. In order to support concurrent engineering two types of data models have been recognized as essential, these are product and manufacturing models.

The application of product and manufacturing models to assist design for manufacture [3], is a key aspect of concurrent engineering. These information models facilitate effective design for manufacture and assist in the selection of manufacturing facilities, ensuring feasibility

The MS was received on 9 August 2000 and was accepted after revision for publication on 11 April 2001.

* Corresponding author: Wolfson School of Mechanical and Manufacturing Engineering, Loughborough University, Leicestershire LE11 3TU, $U K$. of production with existing resources and supporting the generation of manufacturing information.

This paper presents a product model and a manufacturing model, and describes their use to support design for manufacture through a case study. The case study illustrates the implementation of these models for a cylindrical component. The component is considered for manufacture using three different, alternative manufacturing facilities, and in doing so, the case study demonstrates the value of the information models in the redesign of a component. The research presented is related to information modelling and design for manufacture assisted by computers, but is quite distinctive from previously reported work. With respect to information modelling, the product model proposed is not based on the STEP standard [4] (e.g. reference [5]), and even when sharing with reference [6] the goal of depicting product life cycle issues for supporting concurrent engineering activities, the reported model includes a novel and generic approach for representing manufacturing information. This also distinguishes the model from other feature-based representations for computer aided process planning (CAPP) systems, e.g. references [7] and [8].

The approach proposed is complementary to the extensive investigation undertaken on computational support to design for manufacture, mainly dominated by CAPP systems, as research in the area requires 
extensive product and facility information, see references [9] and [10]. The information data models introduced by the authors could be integrated with current approaches to CAPP based on neural networks, e.g. reference [11], or generic algorithms, e.g. reference [12], or to extensive tools which support process design, e.g. reference [9].

\section{DATA MODEL DRIVEN DESIGN}

\subsection{Product model}

A 'product model' (PM) is a computational representation of all relevant information concerning a given product during its life cycle [13]. The underlying structure of the model satisfies all the information requirements for specified application areas. In the context of CAE systems, PMs are referred to as product model databases and their associated management and access algorithms.

A PM is determined by its structure and contents, and its structure is specified by a 'product data model' (PDM) [14]. The structure depends on the nature of the product and on the tools required to model the information and capture the necessary schema and information in a database. The contents are determined by the specifics of the product and by the life cycle activities to be supported by the model. Frequently, product data models and product models are both termed product models; however, in this research, a distinction is made between product data models which provide a structure which enables the essential characteristics of a product to be captured and product models which hold detailed information which models particular products. Thus there can be many different PM instances based on a single PDM.

The development of ISO standard 10303 'Standard for the Exchange of Product Model Data' (STEP), which aims to enable data exchange and sharing between different CAD-CAM systems, is strongly affecting research in the area, promoting a standard specification of information and defining modelling methodologies $[4,15]$. The application of STEP is being explored in particular areas, but difficulties have been encountered due to the variety of engineering applications to be supported and the problems of achieving versatile, yet comprehensive models. Moreover, STEP is based on the physical structure of the product and does not represent the full product life cycle. Therefore, alternative and complementary paradigms have been proposed, e.g. reference [6].

\subsection{Manufacturing modelling}

A 'manufacturing model' (MM) is defined by Molina [16] as: 'an information model which identifies, represents and captures the data, information and knowledge necessary for the description of the manufacturing resources, processes and strategies of a particular enterprise' [17]. This enables the provision of the necessary manufacturing information for the support of the manufacturing decision making in concurrent design of products. There are several proposals about the structure and contents of MMs, including the factory data model research $[18,19]$ and the structure adopted depends on the particular scenario in which the model is designed to be used.

\subsection{The data model driven design concept}

A product design is represented by its completed PM and therefore the activities of a concurrent engineering team are primarily committed to the creation and population of the product's PM. These design activities generally require information about the manufacturing facility which will be used to manufacture the product (see Fig. 1). At the beginning of the design process there is a PDM which can be instantiated (usually in the form of a suitably initialized database); as soon as information is generated by the design process and stored, a particular PM instance begins to be realized, as information within the database. From this point, the members of the team perform their activities using the same PM as a single, shared source and repository of product information. This allows a fluent approach to the management of design activities, which depends more on the information available within the model than on a predicted design plan. In this way, the PM also provides support and integrates volatile and spontaneous tasks which may be necessary between the normal planned actions of the engineering team.

The MM assists the activities concerned with design for manufacture, by setting them in the context of the particular factory selected to produce the product, and by providing data about its production facilities. Occasionally, design activities provide information to the MM, when data relevant to it are generated (e.g. specifications of new tools, particular production process parameters). In such cases, the MM database needs to be updated to reflect the changes in capabilities.

Data model driven CAE systems have been researched at Loughborough University. In part of this work, a reverse engineering process model has been defined [20] and a data model driven CAE system to support it has been specified to enable an approach founded on concurrent engineering principles [21]. Research and experimentation with the system has shown its potential for assisting design for manufacture by information models.

The rest of this paper describes the kernel elements of the proposed CAE system and their capability to assist in several relevant aspects of design for manufacture including the representation of manufacturing information, the redesign of products and the selection of an appropriate site for production. 


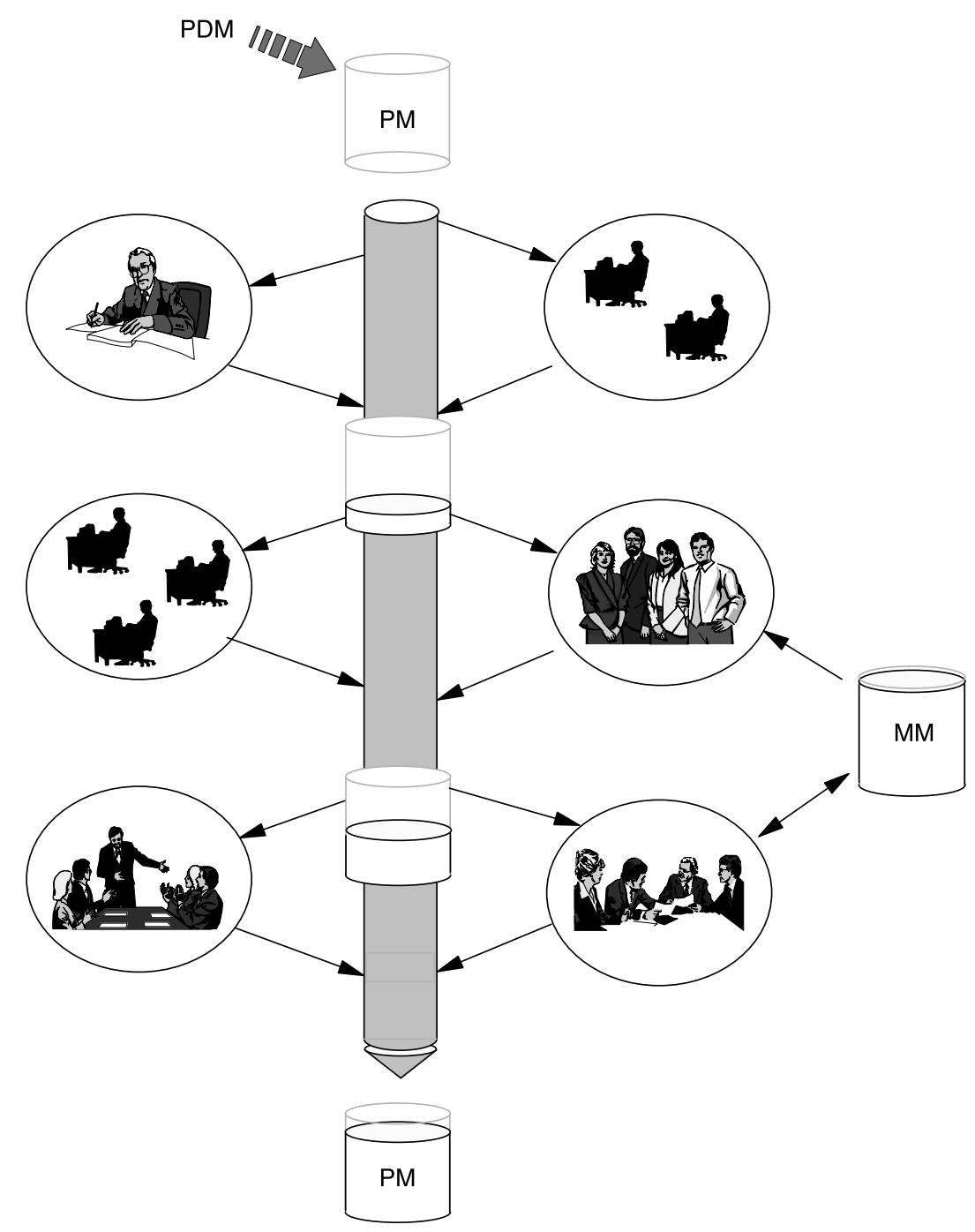

Fig. 1 Concurrent engineering product design activities assisted by data models

\section{THE PRODUCT DATA MODEL (PDM)}

The proposed PDM enables the creation of instances, i.e. PMs, which support various software applications whose functionality includes definition of specifications, assistance in design for function and support for design for manufacture. The support provided for design for manufacture in particular is shown in this paper. The framework of the data model and its schemas are based on generic concepts to allow the representation of a variety of electromechanical products. Nevertheless, their specifics enable rotational components manufactured by machining processes, in particular turning, to be modelled comprehensively.

The PDM is capable of representing: the product structure (physical structure), specifications (desired characteristics from the product), concepts (functional aspects of the product), design characteristics (shape, dimensions, tolerances, surface finishes, materials), manufacturing information (resources and processes required to realize the product) and properties (actual attributes of the product).

\subsection{The PDM framework}

The framework of the PDM is based on the objectoriented paradigm and provides the context for the data structures which represent the information categories outlined by the previous section. The framework, which was influenced by reference [6], is centred on the product's physical structure and the stages of its life cycle.

The classes of the framework and its relationships are shown in the Booch class diagram presented in Fig. 2. Booch notation represents classes by clouds (e.g. 'product' and 'part' in Fig. 2) and semantic associations by lines which may have an addition at one of its ends: inheritance (is $a$ association) is depicted by arrows which point to the parent (e.g. product is a design entity in Fig. 2); aggregation (has association) is symbolized by lines which at the end of the collector class have a 


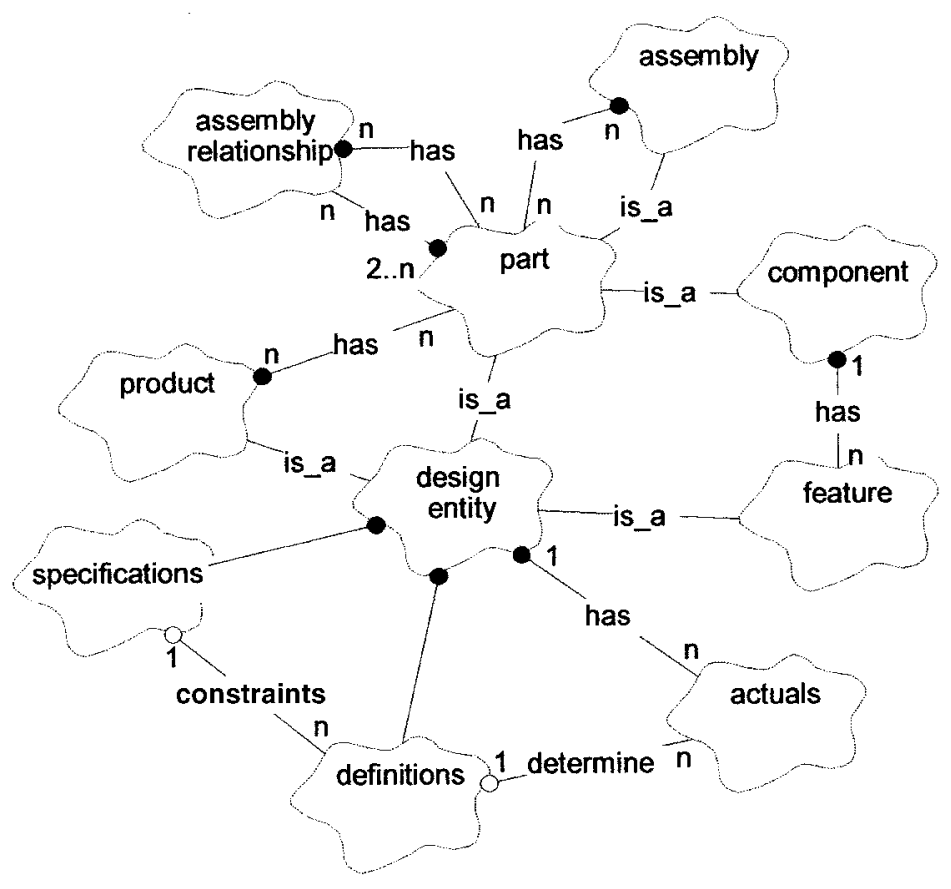

Fig. 2 The framework of the PDM

black point (e.g. design entities have specifications, definitions and actuals); other associations are represented by lines with a white circle at the end of the class on which the association depends (e.g. specifications constrain definitions and definitions determine actuals). The cardinality of the associations is indicated by numbers; to express that one design entity can have many definitions and that each definition corresponds to a single entity, a number one is placed near to the design entity class and the letter $\mathrm{n}$ (many) near to the other.

As illustrated in Fig. 2, the kernel element of the PDM is the 'design entity' class. A design entity is a physical object or element which corresponds to a solution developed through design activities aimed at satisfying a set of requirements. Through its subclasses and their associations (upper part of the diagram), the product structure is represented. The product life cycle of an entity is divided into three stages, which is similar to the approach taken by reference [6]: as specified, as designed and planned for manufacture, and as manufactured. These stages are modelled by the 'specifications', 'definitions' and 'actuals' classes respectively. The 'specifications' and 'actuals' classes are explained elsewhere [3].

The 'definitions' class, and its associated classes, are capable of supporting the redesign of entities by describing them from different perspectives and using a variety of forms. In particular, it describes the functionality (functions performed, and functional structure), physical aspects (geometry, dimensions, tolerances, surface finishes, etc.) and manufacturing information.

Each element of the framework of the PDM is a metaclass and, therefore, all of them are the top classes of distinctive taxonomies, e.g. the 'component' class is the top class of a taxonomy which may consist of standard components, manufactured components, motors, wheels, shafts, axles, nuts, etc. Elements of specific taxonomies are selected to define a particular PM. The authors have addressed the taxonomies needed to represent machined rotational components and to support design for manufacture activities. They include a feature taxonomy derived from the feature class of the framework and two data structures, one to represent physical aspects of design entities and the other to model manufacturing information [3].

\subsection{Representation of manufacturing information within the PDM}

The PDM facilitates consideration of available facilities during design for manufacture, and thereby assists two aspects of the process: (a) the definition of the physical description of entities so that they can be economically manufactured, and (b) the generation of feasible process routes. A 'process route' includes the manufacturing processes, resources and geometrical changes of a design entity through the operations which transform it from an initial stage to the desired product or component. The representation of a process route requires the definition of the initial stage (raw material), the desired stage (desired product) and the intermediate stages of a part or product throughout its manufacturing operations, along with the production processes, manufacturing resources and operation parameters [7].

The MMs model actual manufacturing facilities and work in harmony with the PMs. The PDM represents: 


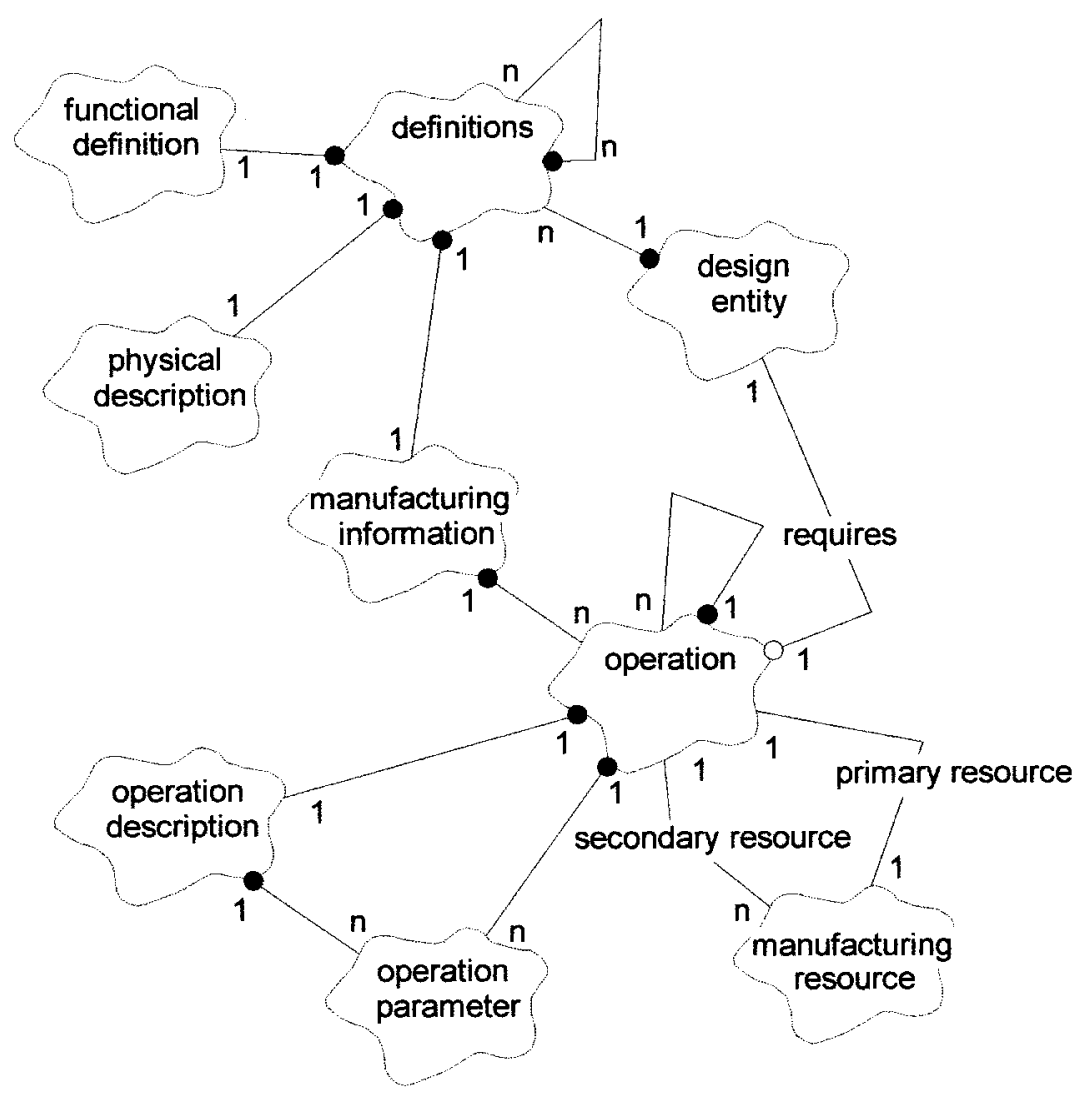

Fig. 3 Manufacturing information classes of the PDM

sequence and description of operations, specific parameters for each of them, and references to the MMs (i.e. processes and resources captured within specific MMs). The 'physical description' class of the data model is detailed in reference [3]. It is part of the 'definitions' class (see Fig. 3) and is capable of storing the geometrical information associated with the initial, final and intermediate stages of the product. This combination of information and flexibility of the MM described below provides a comprehensive support to design for manufacture activities.

The class structure designed to model manufacturing information is presented in Fig. 3. The 'manufacturing information' class contains the raw material, the total manufacturing cost, the number of operations, and the time required to perform them. As can be seen in Fig. 3, manufacturing information has operations associated with it. The operation class can be used to depict different types of operations (e.g. machining, assembly, inspection), but in this paper, the described operation class refers to machining processes. The 'operation' class includes: (a) an operation number, which relates to its sequence in the process route; (b) a production process, which maps to an MM; (c) the time and cost of the operation and (d) a reference to an instruction file which contains data useful for the manufacturing stage, e.g. a numerical control (NC) part program. The 'operation' class also includes an association has to itself to enable the representation of suboperations, e.g. a turning operation has roughing and finishing suboperations.

Specific data for applying production process to manufacture the parts are contained within the 'operation description' class. This class has 'operation parameters' which are defined by a name, a magnitude and units that can represent physical parameters (e.g. diameter, length) and manufacturing parameters (e.g. speed, feed).

The last class employed for the depiction of operations is a 'manufacturing_resource'. This is capable of storing names or identities (IDs) of resources (e.g. machines, tools) captured within MMs. It has two associations with the operation class: (a) 'primary resources' refers to facilities capable of performing the processes, e.g. production machinery, (b) 'secondary resources' refers to facilities that must be present in a process, e.g. production tools.

Figure $4 \mathrm{a}$ shows the classes involved in modelling operations. Figure $4 \mathrm{~b}$ presents a model showing an instance of a turning operation. It can be seen that operation 50 has several suboperations including operations 50-1 and 50-2. The operation description includes two operation parameters. Operation 50 requires one primary resource and two secondary resources. There are several operation parameters and speed is one of them. Figure $4 \mathrm{c}$ illustrates a simplified representation of the instance in a tabular form. 
a) Representation of manufacturing operations within the PDM

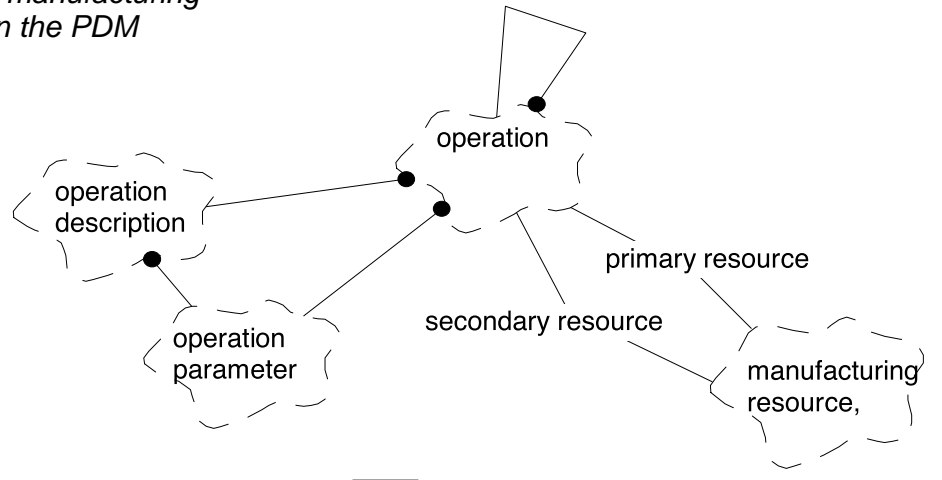

b) Particular operation instance
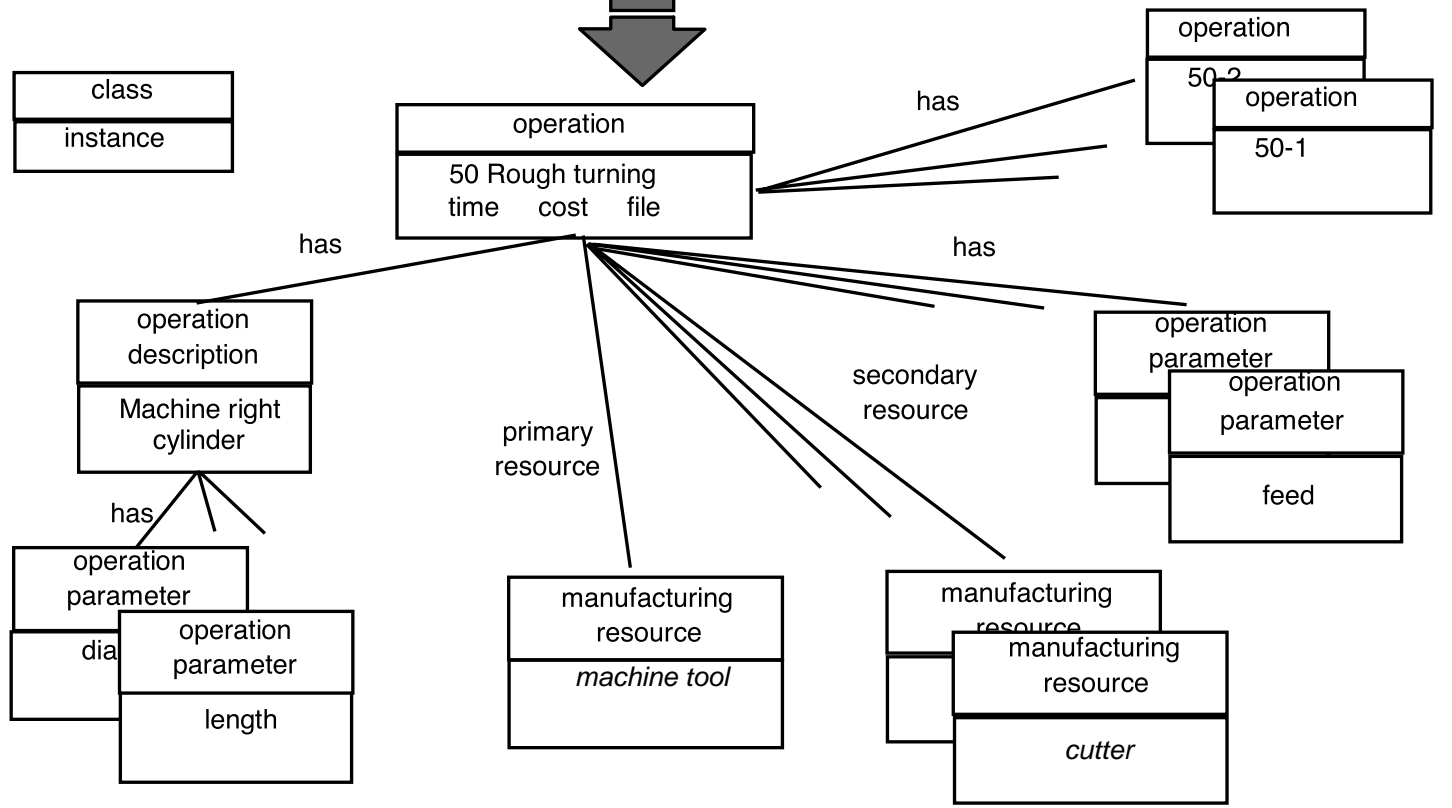

c) Simplified relational representation

\begin{tabular}{|c|c|c|c|c|c|c|c|c|}
\hline \multicolumn{9}{|c|}{ operation } \\
\hline $\begin{array}{l}\text { Op. } \\
\text { No. }\end{array}$ & $\begin{array}{l}\text { Process } \\
\text { type }\end{array}$ & $\begin{array}{l}\text { Operation } \\
\text { description }\end{array}$ & $\begin{array}{l}\text { Primary } \\
\text { resource }\end{array}$ & $\begin{array}{l}\text { Secundary } \\
\text { resource }\end{array}$ & $\begin{array}{l}\text { Technical } \\
\text { parameters }\end{array}$ & Time & Cost & $\begin{array}{l}\text { Inst. } \\
\text { File }\end{array}$ \\
\hline 50 & $\begin{array}{l}\text { Rough } \\
\text { turning }\end{array}$ & $\begin{array}{l}\text { Machine right cyl } \\
\text { D102.025 L53.5 } \\
\text { cyl D114 L75 }\end{array}$ & machine tool & $\begin{array}{l}\text { Insert: } \\
\text { Insert holder: }\end{array}$ & $\begin{array}{l}\text { feed } \\
\text { speed }\end{array}$ & & & \\
\hline
\end{tabular}

Fig. 4 Representation of operations using the PDM

While the references to processes and resources within the MMs can be established using their names or IDs, the concept of 'intermediate entity' is employed to represent the geometry related to manufacturing operations. An intermediate entity is a part of an intermediate stage of its manufacturing process route. An intermediate entity is represented by the design entity class and is created using the association requires which links the 'operation' class with the 'design entity' class (Fig. 3).
An intermediate entity is not part of the structure of a product and does not have functional information, but contains the same attributes that any design entity possesses. Therefore, an intermediate entity can be a part or a feature integrated with other entities, e.g. an intermediate component has features. Besides, an intermediate entity has physical and manufacturing descriptions, so geometry and process route information can be associated with it. 
In this way, instances of the manufacturing operation class may: (a) represent an operation of a process route which does not require an intermediate entity, e.g. the last one; (b) depict operations which do not affect the entity's design characteristics; or (c) include a reference to an intermediate entity, which represents both the physical description and the manufacturing data of an operation.

Hence, considering the data structure discussed above for representing manufacturing information, the process route of a product or part is represented by the finished entity and its manufacturing information which includes the raw material and associations to operations. Different process routes for an entity can be modelled by creating definitions of the entity with distinctive manufacturing information. Therefore, the PDM is capable of representing alternative process routes which may consider diverse types of manufacturing processes and resources.

\section{THE MANUFACTURING DATA MODEL (MDM)}

The MDM captures manufacturing capabilities and, in particular, those required for manufacturing machined rotational components. The MDM is based on Molina [16] and its core element is the 'facility' class (Fig. 5). In reference [17], Molina and Bell define a facility as 'any type of system which allows the manufacturing of entities'. The structure adopted here includes two types of facilities, i.e. 'cell' and 'station'. Each facility has 'manufacturing processes' and 'manufacturing resources' associated with it.

The authors define a manufacturing process as a procedure which: (a) changes the geometry, tolerances, surfaces or material properties of an entity (e.g. chipforming processes, forming processes, assembly, heat treatments); (b) measures its properties (e.g. inspection); (c) handles it (e.g. fixturing operations, transport, storage) or (d) combines any of the previous cases. Manufacturing resources are taken to be all the physical elements within a factory which enable product realization, such as: production machinery, production tools, material handling equipment, storage systems, humans, supply and disposal units, etc. [22].

The MDM represents manufacturing capabilities based on achievable process types, dimensions, tolerances and surface finishes, by the available resources. This method is appropriate for modelling specialized cells, such as the ones used in group technology. In the

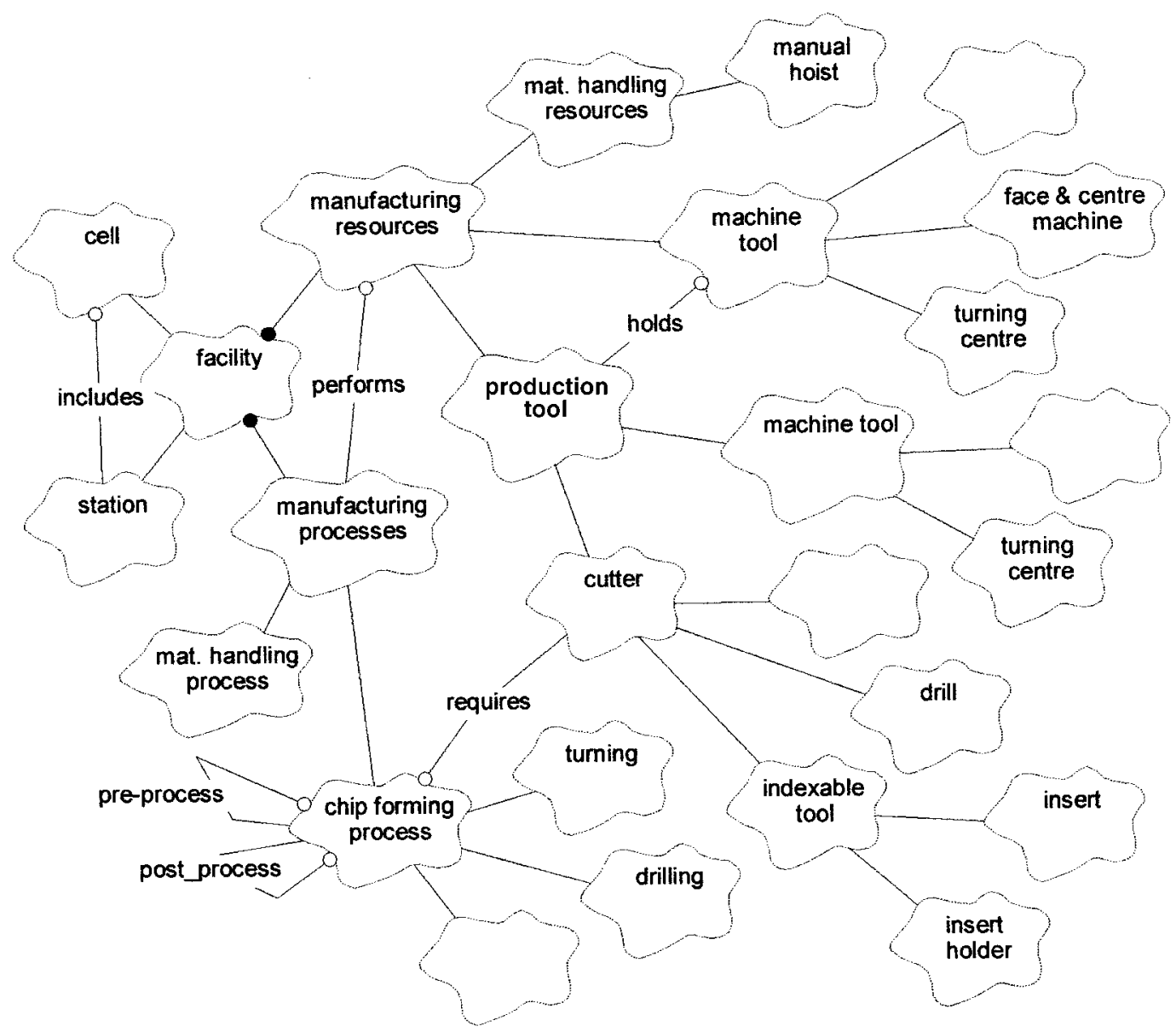

Fig. 5 The manufacturing data model 
data structure (Fig. 5) there is no distinction between turning and milling tools. They are both considered to be 'indexable tools'; the attributes of the class, along with the particular inserts and insert holders associated with it, make the distinction. The same applies to different types of processes; e.g. facing, external roughing, internal finishing, boring and grooving are all considered to be turning processes.

The model includes relationships between processes, machines and tools which are depicted by the associations requires, holds and performs. In order to associate cutters with machine tools it is necessary to observe the following: a relatively small number of processes (e.g. processes performed by a station to produce a specific family of parts) are to be modelled; the machine components and accessories to hold the workpiece and the cutter (turret, cutter holder, chuck, tail stock, centres, etc.) have been considered before setting the association; it is certain that the machine capabilities satisfy the requirements of the processes associated with the cutter.

The method introduced is efficient for modelling cells which produce a particular range of products because it represents the required amount of machines and tools information within only a few classes. The MDM association performs which exists between manufacturing processes and resources (Fig. 5) is set at the highest level in the taxonomy. It is important to note that it is not applicable to production tools, it is meant for the resources which hold them, i.e. machine tools. In the developed model, the association performs is used to assign processes to machine tools and material handling resources.

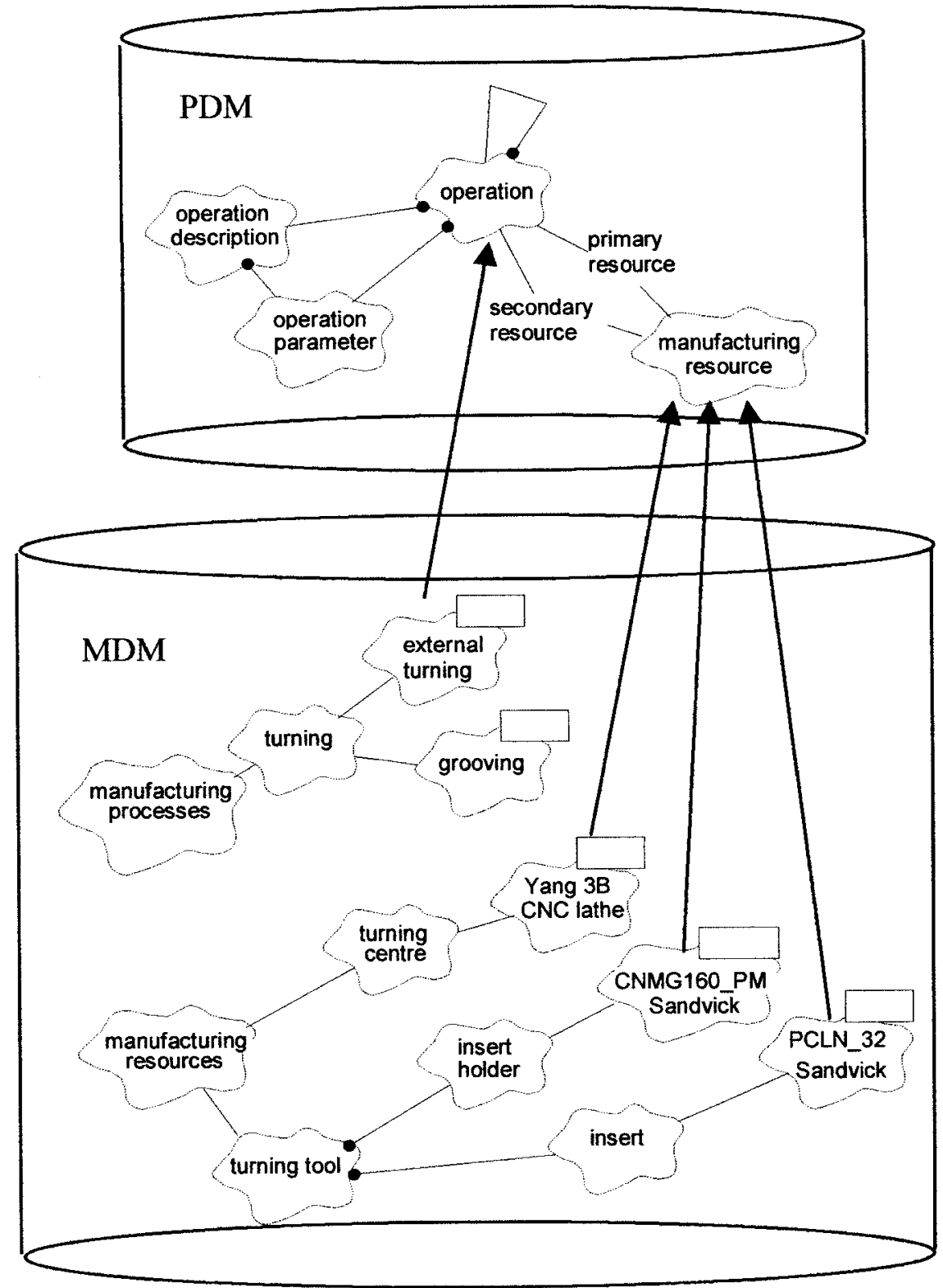

Fig. 6 Relationship between the PDM and the MDM 


\section{THE REPRESENTATION OF MANUFACTURING INFORMATION USING DATA MODELS}

Figure 6 highlights the combined use of a product model and a manufacturing model for modelling the manufacturing information of a product. The figure shows that particular instances of the MM, in this case the one representing the manufacturing process 'external turning' and three Manufacturing Resources, provide information to the classes 'operation' and 'manufacturing resource' of a particular instance of a PM.

The PM contains product-specific information which identifies the processes and resources selected for its manufacture. These processes and resources are detailed within the MM of the actual site, or sites, planned for manufacture. The information made available by both models is capable of providing sufficient support to enable data model driven applications to undertake design for manufacture and generate manufacturing information [21].

\section{THE CASE STUDY}

The application of the PDM and MDM in supporting design for manufacture activities has been investigated through a case study, in which the scenario is the redesign of a component through consideration of specific manufacturing sites. To do this, it is necessary to retrieve information about a component held in a PM and evaluate it using manufacturability principles, in order to assess the suitability of using specific manufacturing sites for its production, and thereby define the manufacturing information related to a particular facility. The case study, which was carried out in collaboration with a company, included the design and implementation of the data models described above and of application software to test the models and assist in design for manufacture activities. The case was focused on the redesign of a stepped axle. The finished component is shown in Fig. 7.

\subsection{The representation of the manufacturing information for the case study component}

Figure 8 depicts instances of the main classes of the PDM involved in the representation of manufacturing information, i.e. 'component', 'physical description', and 'manufacturing information'. Instances of the classes 'part', 'design entity' and 'definition', which are also part of the framework of the PDM (Section 3.1), have not been included as the case study example has been simplified for demonstration purposes.

The figure represents the manufacturing information of a component called 'axle' with a simplified physical description illustrated by the graphic at the top left of the figure (the physical description class is detailed in reference [3]).

Figure 8 illustrates that the class component is associated with an instance of the manufacturing information class. This is done through other classes of the framework (see Figs 2 and 3) which are not included in the figure as explained above. The manufacturing information class is associated with several instances of the operation class and they together hold the manufacturing data of the component as detailed in Section 3.2. Note that Fig. 8 uses the same simplified tabular representation introduced in Fig. 4.

The PDM is capable of supporting different criteria for defining intermediate entities and operations. In the example presented in Fig. 8, an operation is considered for each process type required to produce the case study component and an intermediate component was defined for operations which change the component geometry in a significant way. Hence, operation number 10 includes the specifics of a sawing operation, and operation number 110 describes a drilling process. The figure presents operations 30, 50 and 60 as examples which use the association requires described in Section 3.2 to intermediate components A, B and C.

Figure 9 shows the data represented by the intermediate component $\mathrm{B}$. As can be seen, one of the advantages of the data structure of the proposed PDM

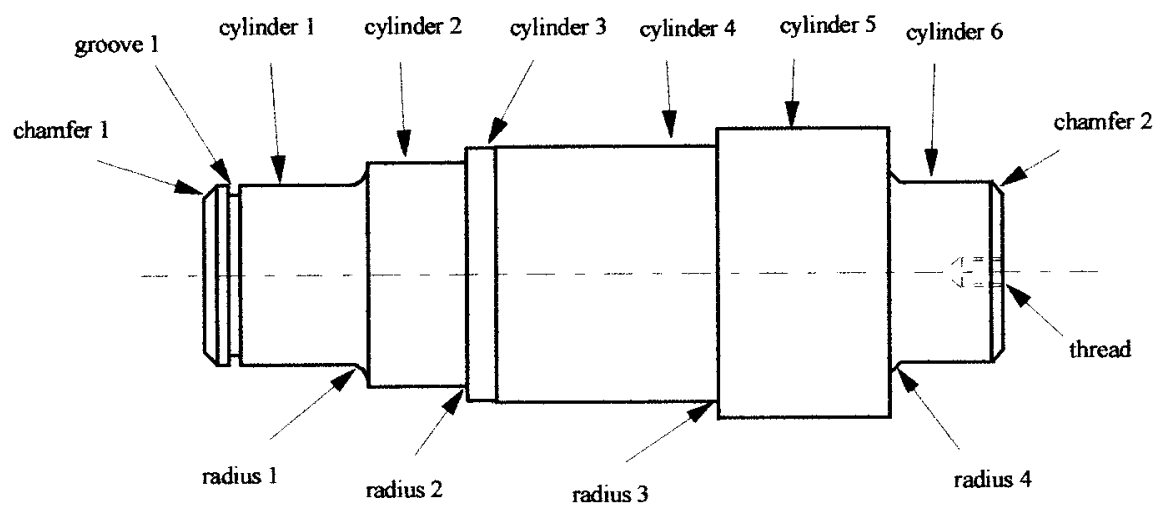

Fig. 7 The axle for the case study 


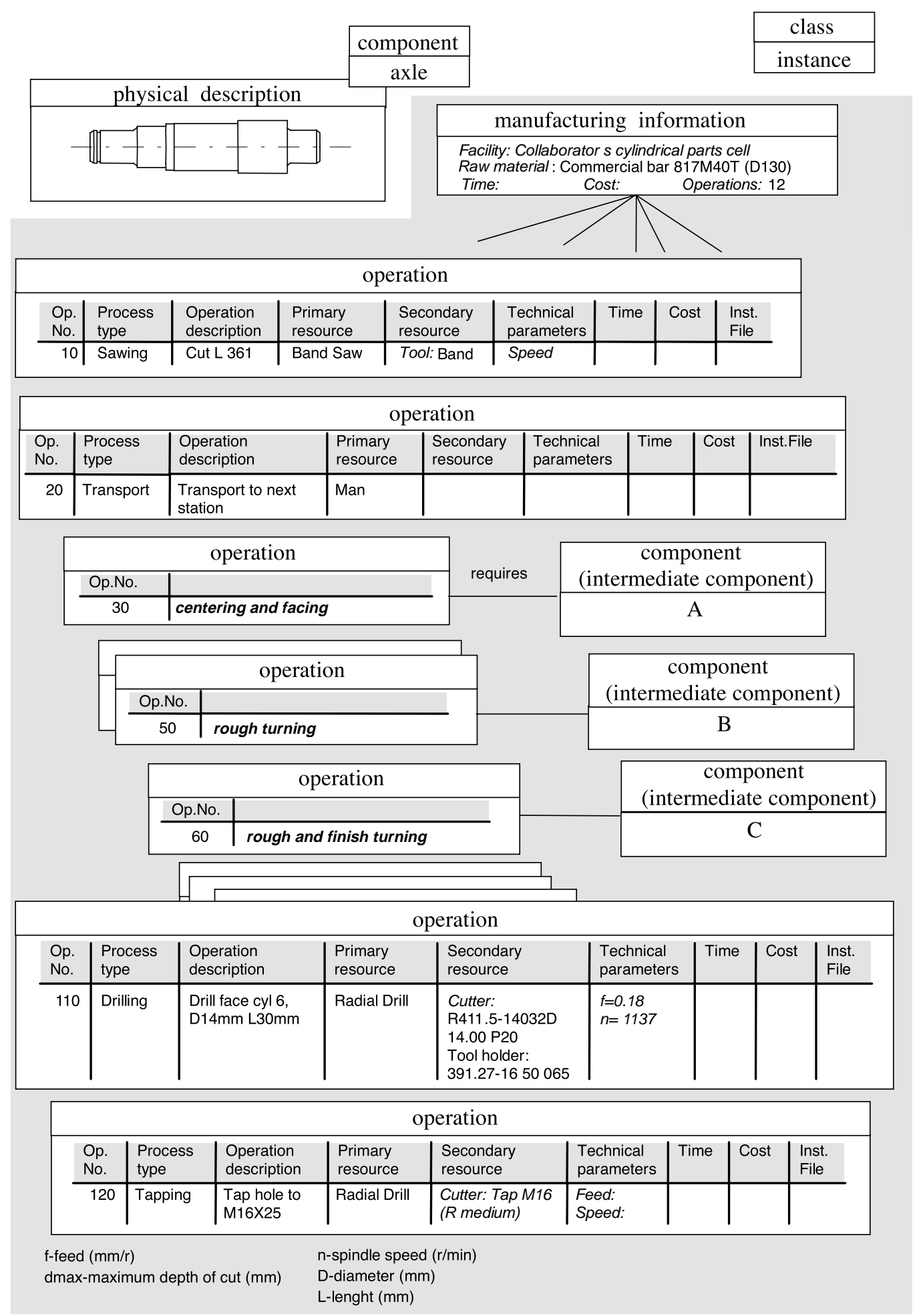

Fig. 8 Instances of the PDM representing manufacturing information

is that it enables the description of detailed manufacturing information to be associated to the evolving geometry of the component through its production process. In this case, the physical description of the figure corresponds to the one produced by the operations of the intermediate component. The intermediate component $\mathrm{B}$ describes each pass of a rough turning operation and is an example of the use of the has association of the operation class to itself (Fig. 3). The figure represents the operation 50 which has operations 52 to 58. Operation 50 contains the general aspects of the operation while the other operations (i.e. 52, 54, 56, 58) describe the details of the passes required to achieve the geometry specified by operation 50 . 


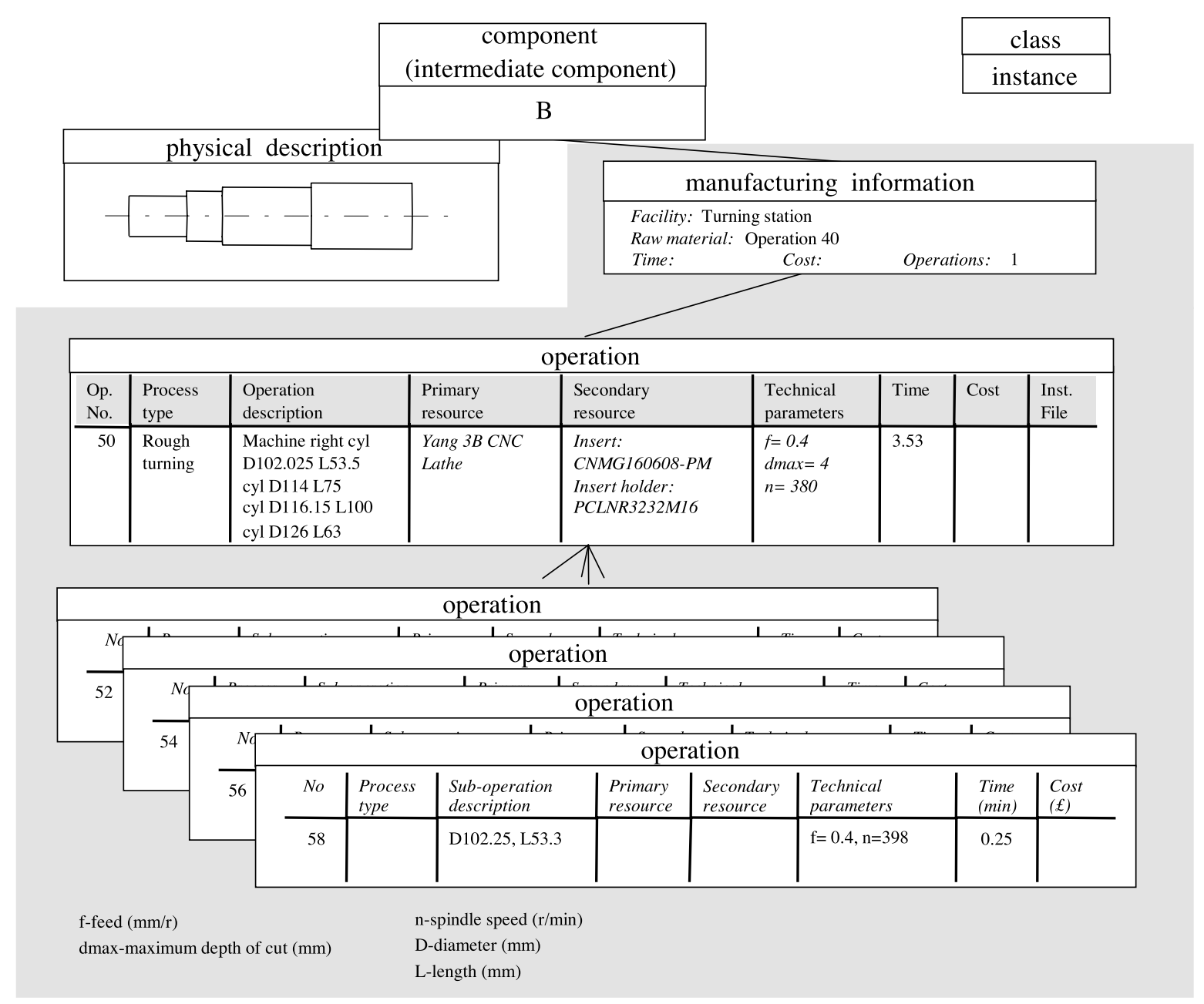

Fig. 9 Intermediate component B

It is important to highlight that even though the manufacturing sector of the PDM is compatible with the data modelled by the MDM, there is no direct link between them. It is the task of a software application to retrieve data from MMs (i.e. elemental information about processes and resources) and store it into PMs. In this way, both models remain independent from each other. Consequently, different approaches can be used to represent manufacturing capabilities and still be used in combination with the PDM. The requirement from the MDM is that it should provide detailed descriptions of processes and resources, e.g. cutting angles and nose radii of the tools, and cost and capacities of the processes.

\subsection{The representation of possible sites for production}

Three manufacturing sites were modelled for the case study using the MDM described in Section 4. They were a cylindrical parts cell of the collaborating company ('Collaborator's_cell'), a hypothetical cell composed of a double spindle turning centre ('Hypothetical_cell'), and a cell composed of some equipment from the machine laboratory of Loughborough University ('LU_cell').

Figure 10 presents a simplified diagram of the MM of the LU_cell. In the figure, only the instances of the MDM (see Fig. 5) containing detailed information are included. Therefore, even when they are present in the data structure, the classes facility, manufacturing resources chip-forming processes, manufacturing resources, machine tool production tool, cutter and material handling resources, are not included in the figure. The cell depicted has two stations and a manual hoist, and the associations has and includes were used to link them. The stations include resources, which are machine tools and tools, and processes. Therefore, interpreting the diagram, the station LU_1 includes a 'turning centre' called DSG 500TC. Two of the tools used, or held, by this machine are 'indexable tools' called rough_right_1 and rough_left_2. The turning processes 'roughing_R1' and 'roughing_L1' are examples of the processes that the machine tool can perform with the above-mentioned tools (see Fig. 10). In the case study, all three cells were modelled using purpose-written software which was designed and 


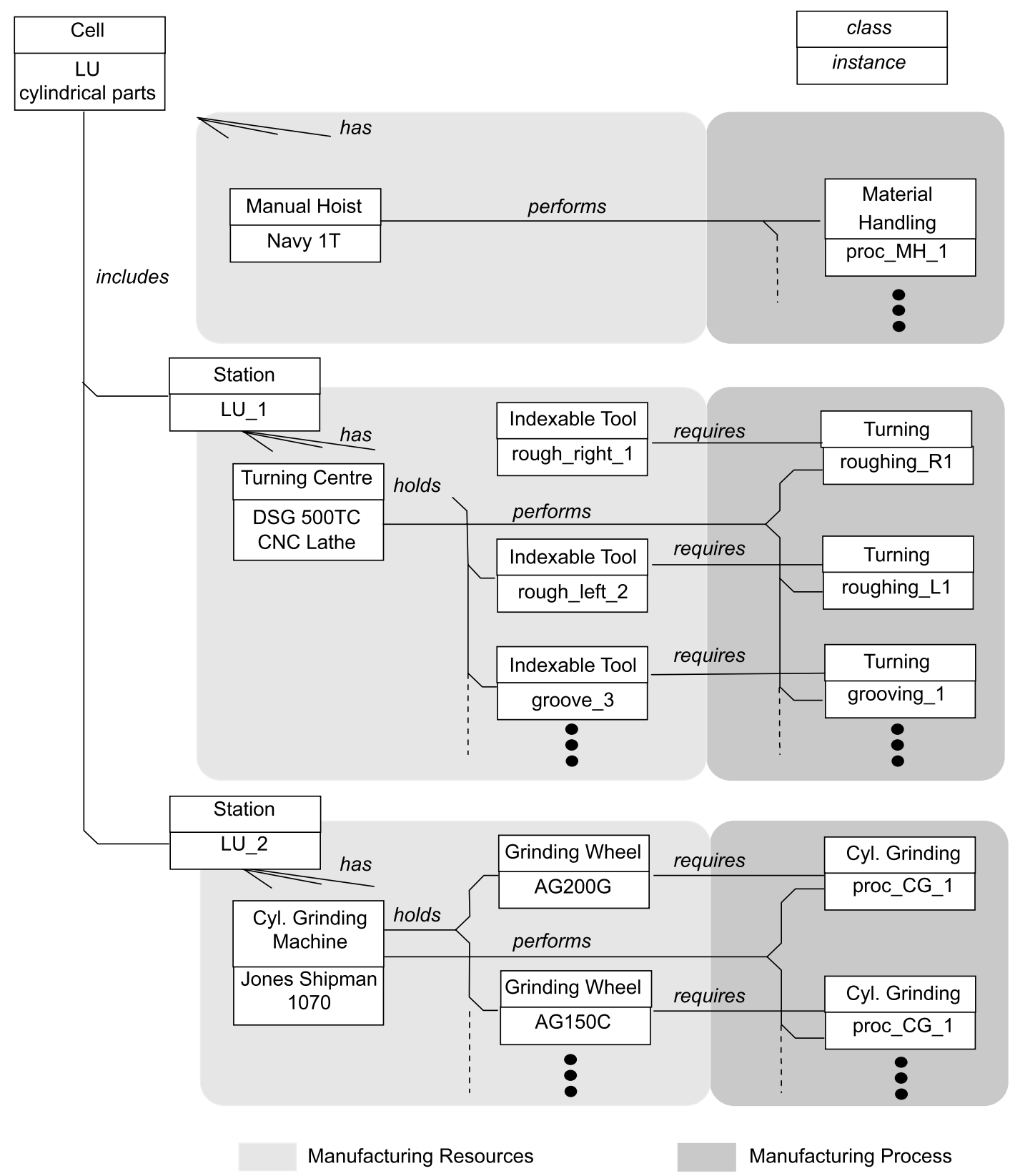

Fig. 10 Representation of the LU cell

implemented by the authors. These applications create, populate and modify MMs.

\subsection{The use of the data models for redesigning a component}

To explore the application of the PDM and the MDM, further software which supports design for manufacture was implemented, this was called 'the turning agent' [23]. The agent assists redesign by (a) checking that the component includes design for manufacturability principles, (b) assessing the viability of manufacturing components in the sites represented by MMs and (c) specifying manufacturing information. The first activity is described further in reference [23]. In contrast, this paper focuses on the other two activities as they illustrate the advantages of the PDM and the MDM working together to support design for manufacture.

In order to assess the viability of manufacturing in the sites represented by MMs, the turning agent compares the requirements of manufacturing the components with the capabilities of facilities. In order to do so, the agent extracts data related to the physical description of the component from within its PM, and looks for manufacturing processes in MMs capable of achieving it. Figure 11 presents the results obtained with the agent after assessing one manufacturing cell during the case study.

In the case study, the Collaborator's_cell, the Hypothetical_cell and the LU_cell, were used to redesign 


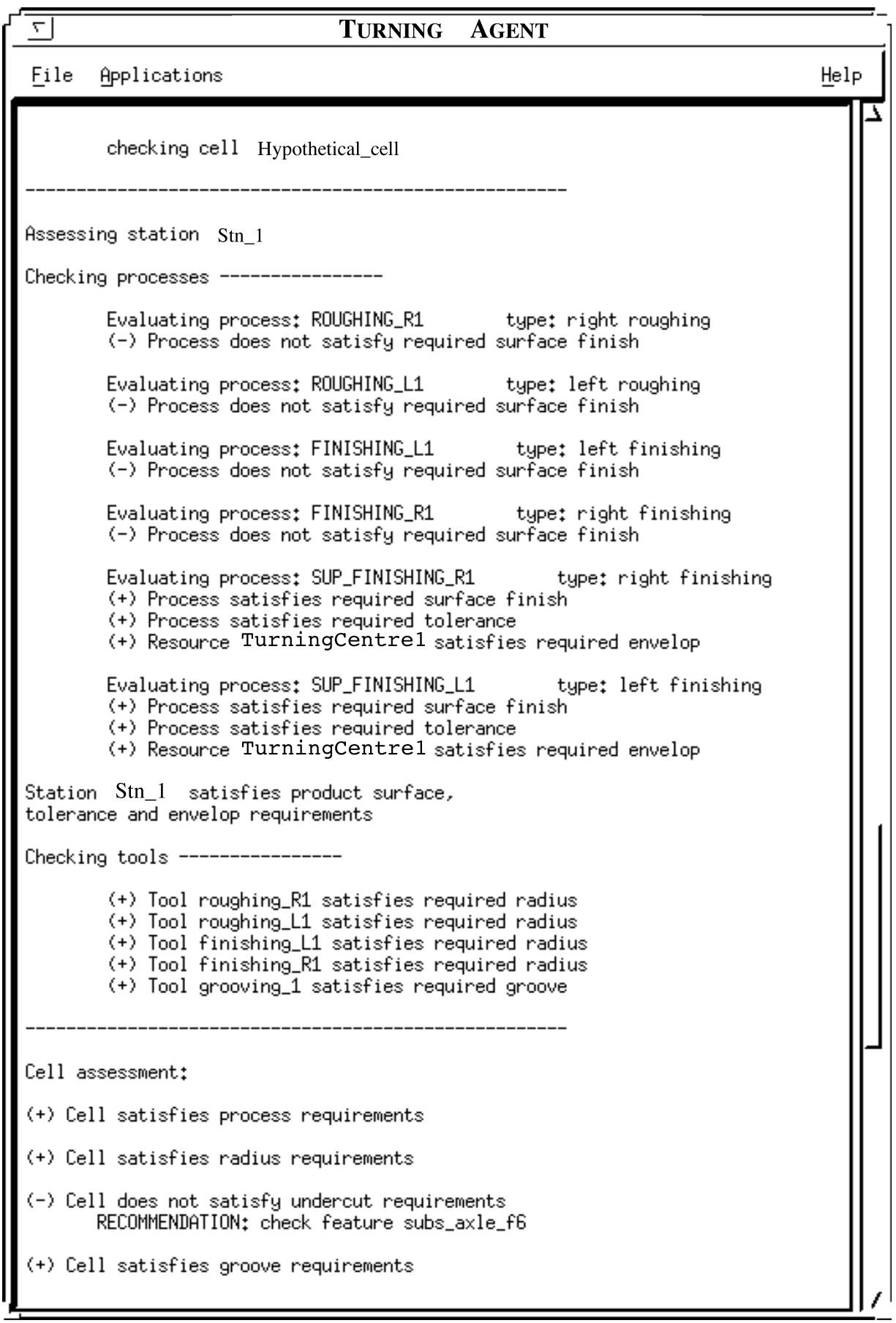

Fig. 11 Initial assessment of the Hypothetical_cell

a stepped axle. The figure shows that the surface finishes achieved by each process performed by Station 1 (e.g. ROUGHING_R1, ROUGHING_L1) of the Hypothetical_cell were verified during the corresponding assessment. When a process satisfied the surface requirement (e.g. SUP_FINISHING_R1), the tolerance of the component was checked and, after this, the envelope capabilities of the machine tool which performs the process were verified. A final assessment of the station is displayed after checking all the processes.
The next evaluation carried out by the turning agent was tool availability. Figure 11 presents the results obtained from comparing the sizes of the radii, grooves and undercuts of the component against the capabilities of the tools of the Hypothetical_cell. From the tool assessment, it can be seen that no problem was found with the radii or the grooves of the component. However, in the final evaluation of the cell, a problem and a recommendation are indicated. No forming tool for undercuts was modelled in any of the cells, therefore, as expected, 
the agent notified about this problem identifying the feature of the component which should be modified, in this case 'subs_axle_f6'.

During the case study, in the assessment of the LU_cell, the turning agent checked two stations: a lathe and a cylindrical grinding machine. The agent indicated that the lathe did not satisfy the required surface finish and the grinding machine could not machine the length of the component. In the assessment of this cell, the designer was advised to check the component. The problem with the undercut discussed above was also found in the cell. The feature subs_axle_f6 of the component was modified for a radius and the turning agent was used again to assess the cells. After correction of the component, the Collaborator's_cell and the Hypothetical_cell were found to be suitable for manufacturing the component.

It is important to note that the problem presented by the component in the first assessment of the cells could have been approached in two ways: either by redesigning the component or by modifying the capabilities of the cell so that the desired component can be manufactured. In this case study the first approach was demonstrated. The other approach would have implied the inclusion of a cutter which satisfied the component requirements in the manufacturing model of the cells. The second assessment of the LU_cell verified that the cell was not suitable for manufacturing the component unless its dimensions were modified so that it could be machined by the grinding machine belonging to the facility.

The turning agent is also capable of specifying manufacturing information. When a facility has been selected to manufacture a component, the agent specifies the manufacturing operations required to produce it. This is done by creating and populating instances of the PDM's data structure detailed in Section 3.2 through a simplified computer aided processes planner. The information included in the component's PM includes the dimensions of the raw material, the specification of intermediate components and their manufacturing operations as described in Section 6.1. The details of this activity were not included in this paper but can be reviewed in reference [3]. During the description of the manufacturing operations, once more the availability of the PM and of the MM enables process and resource information to be retrieved and stored. In addition, the data on the geometry, surfaces and tolerances held in the PM may be employed to calculate the technical aspects (e.g. feed, depth, length and diameters, etc.) of the operations.

At the end of the redesign process, the detailed description of the substitute component, including its manufacturing information, is captured within its PM. It is important to reiterate and emphasize that the manufacturing information includes the detailed description of the operations associated to the evolving geometry during the production process, and information retrieved from the MM selected for the manufacture.

\section{CONCLUSIONS}

This paper presents an original view of the way in which product data models and manufacturing data models can be populated to support the design process. It has described an original product data model and manufacturing data model. The representation of product information, in particular manufacturing information, and the documentation of production facilities has been illustrated. The extensive and generic approach proposed, models manufacturing information within the product model, and consequently is distinctive from competitive work on data modelling [6].

The combined utilization of the information models, which have been introduced by the authors, to assist the design for manufacture has been shown. This was done by a case study that evaluated the viability of manufacturing a component in three specific manufacturing sites and specified its manufacturing information. The concepts proposed in this paper can be integrated with actual work on CAPP systems based on artificial intelligence, e.g. reference [11], evolutionary computing, e.g. reference [12], or to more extensive support for concurrent product and process design similar to that proposed by reference [9].

The research reported here focuses on the use of product and manufacturing models as kernel elements of data model driven CAE systems. It has also demonstrated the potential benefits offered by the simultaneous use of these repositories of information in supporting design for manufacture, which is a key aspect of concurrent engineering.

\section{ACKNOWLEDGEMENTS}

The research undertaken by V. Borja was funded by the National and Autonomous University of Mexico (DGAPA-PAPIIT IN110398) and the CONACYT (J27775U). The authors wish to thank their research colleagues in the Wolfson School of Mechanical and Manufacturing Engineering at Loughborough University who have provided helpful discussion throughout the research.

\section{REFERENCES}

1 Prasad, B. Toward a functional design of a concurrent information modeling system. Computing Modeling and Simulation in Engng, 1996, 1, 7-29.

2 Molina, A., Al-Ashaab, A. H., Ellis, T. I. A., Young, R. I. M. and Bell, R. A review of computer aided simultaneous engineering systems. Res. Engng Des., 1995, 7, 38-63.

3 Borja, V. Redesign supported by data models with particular reference to reverse engineering. Doctoral thesis, Department of Manufacturing Engineering, Loughborough University, Leicestershire, September 1997. 
4 ISO 10303-1 Industrial Automation Systems-Product Data Representation and Exchange-Part 1: Overview and Fundamental Principles. International Standard, 1994.

5 Usher, J. M. A STEP-based object-oriented product model for process planning. Computers and Ind. Engng, 1996, 31(1/2), 185-188

6 McKay, A., Bloor, M. S. and de Pennington, A. A framework for product data. IEEE Trans. Knowledge and Data Engng, 1996, 8(5), 825-838.

7 Juri, A. H., Saia, A. and de Pennington, A. Reasoning about machining operations using feature-based models. Int. J. Prod. Res., 1990, 28(1), 153-171.

8 Xue, D. and Dong, Z. Coding and clustering of design and manufacturing features for concurrent design. Computers in Industry, 1997, 34, 139-153.

9 Klocke, F., Fallböhmer, M. and Trommer, G. Methods and tools supporting modular process design. Robotics and Computer Integrated Mfg, 2000, 16, 411-423.

10 Pham, D. T. Intelligent product design and manufacture model. In Artificial Intelligence in Design, 1991, Ch. 7, pp. 147-168 (IFS Springer-Verlag, London).

11 Du, T. Ch. T. and Wolfe, P. M. Implementation of fuzzy logic systems and neural networks in industry. Computers in Industry, 1997, 32, 261-272.

12 Dereli, T. and Filiz, I. H. Optimisation of process planning functions by genetic algorithms. Computers and Ind. Engng, 1999, 36, 281-308.

13 Krause, F.-L., Kimura, F., Kjellberg, T. and Lu, S. C.-Y. Product modelling. Ann. CIRP, 1993, 42(2), 695-706.

14 McKay, A., Bloor, M. S. and de Pennington, A. Realising the potential of product data engineering. In Proceedings of the 5th International Conference on Factory 2000,
Churchill College, Cambridge, 2-4 April 1997, Conference Publication 435, pp. 403-410 (Institution of Electrical Engineers, London)

15 Fowler, J. STEP for Data Management, Exchange and Sharing, 1995 (Technological Appraisals, UK).

16 Molina, A. A manufacturing model to support data-driven applications for design and manufacture. Doctoral thesis, Department of Manufacturing Engineering, Loughborough University, Leicestershire, 1995.

17 Molina, A. and Bell, R. A manufacturing model representation of a flexible manufacturing facility. Proc. Instn Mech. Engrs, Part B, Journal of Engineering Manufacture, 1999, 213(B3), 225-245.

18 Harding, J. A., Yu, B. and Popplewell, K. Information modelling: an integration of views of a manufacturing enterprise. Int. J. Prod. Res., 1999, 37(12), 2777-2792.

19 Yu, B., Harding, J. A. and Popplewell, K. A reusable enterprise model. Int. J. Ops Managmt, 2000, 20(1), 50-69.

20 Borja, V., Harding, J. A. and Toh, K. T. K. Product reengineering process using an enterprise modelling architecture. Int. J. Agile Managmt Systems, 2000, 2(3), 214-224.

21 Borja, V., Harding, J. A. and Bell, R. A conceptual view on data model driven reverse engineering. Int. J. Prod. Res., 2001, 39(4), 667-687.

22 Molina, A., Ellis, T. I. A., Young, R. I. M. and Bell, R. Modelling manufacturing capabilities to support concurrent engineering. Concurrent Engng: Res. and Applic., March 1995, 3(1), 29-42.

23 Borja, V., Bell, R., López, M., Santillán, S. D. and González, L. A. The use of data models to redesign for manufacture: the turning agent. In Proceedings of the 12th International Conference on Engineering Design (ICED), 1999, 17691772. 
